\title{
DIAGNOSE FOLIAR E PRODUÇÃO DE LARANJA LIMA (Citrus sinensis L. OSBECK) EM FUNÇÃO DE ADUBAÇÕES ORGÂNICA E MINERAL
}

\author{
Paulo Ricardo Aprígio Clemente(1), Vinicius Santos Gomes da Silva(1), Igor Tenório Marinho da Rocha(1), José \\ Paulo Vieira da Costa(1), Lígia Sampaio Reis(1)
}

\begin{abstract}
${ }^{1}$ Centro de Ciências Agrárias, Universidade Federal de Alagoas, BR 104 Norte, Km 85, Rio Largo, AL.
*Autor para correspondência: Paulo Ricardo Aprígio Clemente, pauloclemente_645@hotmail.com
\end{abstract}

\begin{abstract}
Resumo-A citricultura, no Nordeste do Brasil, é explorada predominantemente por produtores com áreas menores do que 10 hectares. De um modo geral, os pomares cultivados em Alagoas apresentam redução significativa a cada colheita devido ao baixo nível de fertilidade do solo e à deficiência nutricional das plantas. No presente estudo avaliou-se a diagnose foliar e a produção de laranja lima submetida a adubações orgânica e mineral. 0 experimento foi conduzido no município de União dos Palmares, Alagoas. O delineamento experimental utilizado foi o de blocos casualizados com 7 tratamentos: 6 materiais fertilizantes (1-composto Uruba, 2-composto Pindorama, 3-composto Coruripe, 4-composto Triunfo, 5-Esterco, 6-Adubo mineral) e um tratamento adicional correspondendo ao controle (sem adubação) com quatro repetições. A diagnose foliar foi realizada coletando-se oito folhas em cada planta três meses após a aplicação dos tratamentos. Constatou-se diferença significativa nos teores foliares de $\mathrm{P}$, com valor médio de $1,4 \mathrm{~g} \mathrm{~kg}^{-1}$. Não houve diferença significava nos teores foliares de $\mathrm{N}$ e $\mathrm{K}$, sendo os valores médios desses nutrientes 30,6 e 10,9 $\mathrm{g} \mathrm{kg}^{-1}$. Também não foi verificado efeito dos tratamentos nas variáveis quantidade e peso de frutos.
\end{abstract}

Palavras - chaves: fertilizantes, nutrientes, doses

\section{DIAGNOSIS AND LEAF PRODUCTION OF LIME ORANGE (Citrus sinensis L. OSBECK) AS A FUNCTION OF ORGANIC AND MINERAL FERTILIZATION}

\begin{abstract}
Producers with smaller areas than 10 acres exploit the culture of citrus in Northeastern Brazil, predominantly. In general, the cultivated orchards showed a significant reduction in Alagoas each harvest due to low soil fertility and plant nutritional deficiency. In the present study we evaluated the leaf analysis and the production of lime orange subjected to organic and mineral fertilizers. The experiment was carried out in the city of União dos Palmares, Alagoas. The experimental design was randomized blocks with 7 treatments: 6 fertilizer materials (1-Uruba compound, 2-Pindorama compound, 3-Coruripe compound, 4-composite Triumph, 5-manure, mineral fertilizer-6) and an additional treatment corresponding to the check (without fertilization) with four replications. The leaf analysis was performed by collecting eight leaves on each plant, and was collecting leaves performed three months after the beginning of the treatments. No difference was found to foliar $\mathrm{N}$ and $\mathrm{K}$, and its contents, in average values, were 30,6 and $10,9 \mathrm{~g} \mathrm{~kg}-1$, respectively. It was found a significant difference to the P leaves concentration, with an average value of $1,4 \mathrm{~g} \mathrm{~kg}^{-1}$. There was no significant difference in the quantity and weight of fruit among the treatments.
\end{abstract}

Keywords: fertilizers, nutrients, nutrient rates.

\section{INTRODUÇÃO}

A atividade citrícola é de grande importância socioeconômica para o Brasil, uma vez que contribuiu com 9 bilhões de reais para o PIB nacional na safra de 2010. Dentro do setor agropecuário compreende uma das atividades que mais se destacam na geração de empregos gerando em torno 400.000 empregos diretos e indiretos (Lopes et al. 2011).

Alagoas apresenta situação semelhante ao resto do país, o que reforça a necessidade do Estado em engajar-se no processo de modernização da atividade citrícola (Coelho, 2003), que em seu 
diagnóstico demonstra que juntamente com essas agravantes, a baixa produtividade na região deve-se também à topografia, que favorece a erosão e perda de nutrientes. Somando-se ainda, a estes fatores, a quase totalidade dos produtores de laranja não pratica nenhuma forma de fertilização em seus laranjais em detrimento de uma pequena parcela que utiliza precariamente resíduos orgânicos.

A ausência de práticas que venham favorecer a manutenção da fertilidade do solo, pode ser explicada pela capacidade das plantas utilizarem-se de suas próprias reservas e absorverem bem os nutrientes do solo, por um período relativamente longo (Almeida e Baumgartner, 2002). A adubação, principalmente a nitrogenada, é de grande importância para manter essas reservas nos órgãos permanentes da planta. Fato este verificado após estudos sobre os efeitos de diferentes doses de NPK, comprovando que a produtividade do pomar manteve-se em um nível compatível com a idade das plantas (Duenhas et al. 2002)

Dentro deste cenário, a adequada nutrição mineral da cultura é extremamente importante para contribuir para maiores produções a menores custos. 0 estado nutricional da cultura afeta a produtividade de modo direto e também promove efeitos indiretos, proporcionando maior resistência ao déficit hídrico, quando adequado, pelo maior desenvolvimento do sistema radicular e maior resistência ao ataque de pragas e doenças (Bologna, 2003).

A diagnose foliar tem constituído um processo eficiente de avaliação do estado nutricional das plantas, pois as folhas são os órgãos que, como regra geral, refletem o estado nutricional, isto é, respondem mais às variações no suprimento de nutrientes (Malavolta et al. 1997).
Nesse sentido o presente trabalho tem por objetivo avaliar o estado nutricional e a produção de laranja lima submetida a adubações orgânica e mineral.

\section{MATERIAL E MÉTODOS}

A pesquisa foi desenvolvida em condições de campo, no Povoado Boca da Palha, Sítio Pedro Correia, Município de União dos Palmares, Alagoas. Aárea utilizada apresenta topografia acentuada, com declividade acima de $20 \%$ eestá situada nas seguintes coordenadas geográficas: $36^{\circ} 03^{\prime}$ de longitude, $09^{\circ} 10^{\prime} \mathrm{S}$ de latitude e altitude de $155 \mathrm{~m}$ acima do nível do mar. Sendo as condições de temperatura média anual de $24,5^{\circ} \mathrm{C}$, pluviometria média anual de 1.019 $\mathrm{mm}$, evapotranspiração potencial de $1341 \mathrm{~mm}$ e real de 864 mm, deficiência hídrica total de 477 mm, com distribuição de novembro a março e excedente hídrico total de $155 \mathrm{~mm}$.

0 delineamento experimental utilizado foi 0 de blocos ao acaso com sete tratamentos: seis materiais fertilizantes e um tratamento adicional correspondendo ao controle (sem adubação). Os materiais fertilizantes correspondem a 1-composto Uruba, 2-composto Pindorama, 3-composto Coruripe, 4-composto Triunfo, 5-Esterco de curral, 6-Adubo mineral e testemunha com 4 repetições. Os fertilizantes orgânicos foram confeccionados com materiais disponíveis na região e caracterizados quimicamente (EMBRAPA, 2001), conforme a tabela 1. As doses foram recomendadas em função da análise do solo. No tratamento referente à adubação mineral foram utilizados os fertilizantes uréia, MAP e cloreto de potássio como fontes de macronutrientes e FTE BR 12 para suprir a carência de micronutrientes $(\mathrm{Cu}, \mathrm{Zn}, \mathrm{Mn})$. A unidade experimental foi de três plantas de laranja lima (C. sinensis L.) com dois anos de implantação.

Tabela 1. Análise química dos compostos orgânicos: 1-Uruba, 2-Pindorama, 3-Coruripe, 4-Triunfo e 5-Esterco.

\begin{tabular}{c|c|c|c|c|c|c}
\hline \multirow{2}{*}{ Determinações } & \multirow{2}{*}{ Unidades } & \multicolumn{5}{|c}{ Composto orgânico } \\
\cline { 3 - 6 } & & 1-Uruba & 2-Pindorama & 3-Coruripe & 4-Triunfo & 5-Esterco \\
\hline PB & $\%$ & 10,85 & 9,28 & 7,42 & 6,31 & 6,31 \\
$\mathrm{~N}$ & $\mathrm{~g} / 100 \mathrm{~g}$ & 1,74 & 1,48 & 1,19 & 1,01 & 1,01 \\
$\mathrm{P}$ & $\mathrm{g} / 100 \mathrm{~g}$ & 0,94 & 0,48 & 0,23 & 0,7 & 0,17 \\
$\mathrm{~K}$ & $\mathrm{~g} / 100 \mathrm{~g}$ & 0,31 & 0,51 & 0,47 & 0,35 & 0,26 \\
$\mathrm{Na}$ & $\mathrm{mg} / \mathrm{g}$ & 2500 & 3500 & 4000 & 2500 & 2500 \\
\hline
\end{tabular}

Nota: PB (Proteína bruta); N (Nitrogênio); P (Fósforo); K (Potássio); Na (Sódio). 
A diagnose foliar foi realizada seis meses após a aplicação dos tratamentos, utilizando 24 folhas, sendo oito delas de cada planta. Foram coletadas folhas sadias, livres de ataque de insetos ou danos mecânicos, retiradas da parte mediana dos ramos terminais com frutos do último surto primaveril. As folhas amostradas foram levadas ao laboratório onde foram lavadas com água corrente e destilada e colocadas para secar em estufa de ventilação forçada a $65^{\circ} \mathrm{C}$, por 48 horas. Posteriormente foi passada em moinho de aço inoxádavel. 0 material vegetal finamente moído foi submetido à digestão nítricoperclórica. As concentrações de $\mathrm{P}$ (colorimetria), K (fotometria de emissão de chama) foram determinadas no extrato, enquanto $0 \mathrm{~N}$ foi determinado pelo método Kjeldahl (Malavolta et al. 1997).
Os dados foram submetidos à análise de variância e as diferenças estatísticas entre as médias determinadas pelo teste de Tukey.

\section{RESULTADOS E DISCUSSÃO}

Os resultados da análise de variância para os teores foliares de nitrogênio, fósforo e potássio encontram-se na Tabela 2, de acordo com 0 teste $F$ ao nível de significância de $(P<0,05)$ apenas o teor de fósforo foi influenciado pelos diferentes manejos das adubações orgânica e mineral. A diferença significativa observada nos teores foliares de $\mathrm{P}$ ocorreu entre os tratamentos 2 (composto Pindorama) e 4 (composto Triunfo). Apesar da diferença entre os tratamentos 2 e 4, os conteúdos de $P$ nas folhas indicaram que as plantas estavam devidamente equilibradas em relação a esse nutriente (Quaggio et al., 1997).

Tabela 2. Teores foliares de nitrogênio $(\mathrm{N})$, fósforo $(\mathrm{P})$ e potássio $(\mathrm{K})$ em laranja lima submetida aos manejos de adubações orgânicas e mineral.

\begin{tabular}{|c|c|c|c|}
\hline \multirow[b]{2}{*}{ Tratamentos } & $\mathrm{N}$ & $P$ & $K$ \\
\hline & & g kg-1 & \\
\hline 1-Composto Uruba & $27,66 \mathrm{a}$ & $1,45 a b$ & $8,99 a$ \\
\hline 2-Composto Pindorama & $29,53 a$ & $1,00 \mathrm{a}$ & $9,78 \mathrm{a}$ \\
\hline 3-Composto Coruripe & $29,00 \mathrm{a}$ & $1,75 a b$ & $10,99 a$ \\
\hline 4-Composto Triunfo & $31,29 a$ & $1,90 \mathrm{~b}$ & $11,07 a$ \\
\hline 5-Esterco & $31,73 a$ & $1,30 a b$ & $11,38 \mathrm{a}$ \\
\hline 6-Adubo mineral & $32,06 \mathrm{a}$ & $1,52 a b$ & $11,91 \mathrm{a}$ \\
\hline 7-Controle & $32,06 \mathrm{a}$ & $1,30 a b$ & $12,55 a$ \\
\hline $\bar{F}$ & 0,5 & 2,83 & 2,01 \\
\hline C.V (\%) & $15,22^{\text {ns }}$ & $24,49^{*}$ & $15,69^{\text {ns }}$ \\
\hline
\end{tabular}

Nota: Médias seguidas de mesma letra na coluna, não diferem entre si pelo teste de Tukey $(P<0,05)$.

Comparando-se os teores de nitrogênio, fósforo e potássio nas folhas de laranja lima com os relatados por Cantarutti et al. (2007), constata-se que esses macronutrientes encontram-se em concentrações adequadas uma vez que segundo esses autores o nível crítico de suficiência de $\mathrm{N}$ deve situar-se 23,0 e $27,0 \mathrm{~g}$ $\mathrm{kg}^{-1}$, e os teores de $\mathrm{K}$ devem situar-se no intervalo de 10,0 a $15,0 \mathrm{~g} \mathrm{~kg}^{-1}$. Fernandes et al. (2010), avaliando 0 estado nutricional de seis pomares de laranjeira Pêra (C. sinensis) no Nordeste paranaense, encontraram valores na ordem de 25; 1,1 e 9,4 $\mathrm{g} \mathrm{kg}^{-1}$ de N, P e K respectivamente, corroborando com os resultados desse estudo.
A análise de variância para a quantidade e peso de frutos das plantas, em função dos tratamentos, encontram-se na Tabela 3. Verifica-se pelo teste $F$ ao nível de significância de $(P<0,05)$ que as adubações orgânicas e mineral não proporcionaram diferenças significativas nas variáveis analisadas. Apesar da ausência de diferença estatística, pôde-se constatar variação na produção entre as plantas no campo, possibilitando assim a identificação dos materiais fertilizantes que proporcionaram os melhores resultados de produção entre os tratamentos. Aquantidade de frutos foi maior no composto Pindorama apresentando $75 \%$ a mais que com o composto Coruripe que apresentou a 
menor quantidade de frutos. Já para o peso de frutos 0 composto Pindorama apresentou maior média e sendo
$92,27 \%$ superior ao composto Uruba que apresentou a menor média para o peso de frutos.

Tabela 3. Quantidade e peso médio de frutos de três plantas de Laranja Lima (Citrus sinensis), submetida aos manejos de adubações orgânicas e mineral.

\begin{tabular}{l|c|c}
\hline \multicolumn{1}{c|}{ Tratamentos } & Quantidade de frutos & Peso de frutos $(\mathrm{kg})$ \\
\hline 1-Composto Uruba & $410 \mathrm{a}$ & $070,25 \mathrm{a}$ \\
2-Composto Pindorama & $755 \mathrm{a}$ & $135,07 \mathrm{a}$ \\
3-Composto Coruripe & $429 \mathrm{a}$ & $080,08 \mathrm{a}$ \\
4-Composto Triunfo & $472 \mathrm{a}$ & $075,08 \mathrm{a}$ \\
5-Esterco & $598 \mathrm{a}$ & $105,97 \mathrm{a}$ \\
6-Adubo mineral & $615 \mathrm{a}$ & $106,12 \mathrm{a}$ \\
7-Controle & $689 \mathrm{a}$ & $121,55 \mathrm{a}$ \\
\hline \multicolumn{1}{c|}{ Quadrado Médio } & $70678.61^{\text {ns }}$ & $2442.49^{\text {ns }}$ \\
\hline \multicolumn{1}{c|}{ C.V (\%) } & 36,99 & 36,70 \\
\hline
\end{tabular}

Nota: Médias seguidas de mesma letra na coluna, não diferem entre si pelo teste de Tukey $(P<0,05)$.

O composto da Usina Uruba, composto da Cooperativa Pindorama, composto da Usina Coruripe, composto da Usina Triunfo, esterco, adubo mineral e Testemunha não exerceram efeitos significativos sobre a nutrição mineral, exceto para o fósforo. Os tratamentos controle e composto Pindorama proporcionaram maiores produções de frutos em comparação ao adubo mineral.

\section{REFERÊNCIAS BIBLIOGRÁFICAS}

ALMEIDA, M.C; BAUMGARTNER, J.G. Efeito da adubação nitrogenada e potássica na produção e qualidade de frutos de laranja "Valência". Revista Brasileira de Fruticultura, 2002, 24, 1, 282-2844.

ANUÁRIO BRASILEIRO DAFRUTICULTURA. Brazil Fruit yearbook 2002. Santa Cruz do Sul: gazeta: Ministério da Agricultura Pecuária e Abastecimento, 2002.176 p.

CANTARUTTI, R. B; BARROS, N. F; MARTINEZ, H. E. P; NOVAIS, R. F. Avaliação da fertilidade do solo e recomendações de fertilizantes. Sociedade Brasileira de Ciências do Solo, 2007. 827 p.

COELHO, Y. S. Plano de desenvolvimento e modernização da cadeia produtiva citrus no vale do Mundaú-Alagoas, 2003, 1-4.

DASBERG, S. Nitrogen Fertilization in Citrus. Orchar Ds. Plantand Soil, 1987, Dordrecht. 100 (1/3): 1-19.DUENHAS, L. H; VILAS BÔAS, R.L; SOUZA, C.M.P; RAGOZO, C.R.A; BÜLL, L.T. Fertirrigação com diferentes doses de NPK e seus efeitos sobre a produção e qualidade de frutos de laranja (Citrus sinensis O.) "Valência". Revista Brasileira de Fruticultura, 2002, 24, 1-5.

EMBRAPA. Empresa Brasileira de Pesquisa Agropecuária. Instruções Técnicas da EMBRAPA SemiÁrido n. 53. Preparo de composto orgânico na pequena propriedade. Petrolina - PE, dezembro de 2001, 1-4.

FERNANDES, A. R; REIS, I. N. R. S; NORONHA, $N$. C. Estado nutricional de pomares de laranjeira submetidos a diferentes manejos do solo. Revista de Ciências Agrárias, v. 53, n. 1, p. 52-58, 2010.IBGE, (Rio de Janeiro, RJ), Estimativa de produção agrícola, 2002. Disponível em: <http://www.sidra.ibge.gov.br> Acesso em 20 de setembro de 2006.

MALAVOLTA, E.; VITTI, G.C.; OLIVEIRA, S.A. Avaliação do estado nutricional das plantas. Piracicaba: Associação Brasileira para Pesquisa da Potassa e do Fosfato, 1989, 201p.

MALAVOLTA, E; VITTI, G.C.; OLIVEIRA, S.A. Avaliação do estado nutricional das plantas: princípios e aplicações. Piracicaba: Associação Brasileira para a Pesquisa da Potassa e do Fosfato, 1997, 319p.

QUAGGIO, J.A.; RAIJ, B. VAN; PIZA JÚNIOR, C.L. Frutiferas. In: RAIJ, B. VAN; CANTARELLA, H.; QUAGGIO, J.A.; FURLANI, A.M.C. (Ed.). Boletim Técnico 100 - Recomendações de adubação e calagem para o Estado de São Paulo. 2.ed. Campinas: IAC, 1997, p.119-52. 